\title{
A química no cinema: desvendando cenas de filmes para a ensino- aprendizagem
}

\section{Chemistry in Cinema: Unveiling Movie Scenes for Teaching-Learning}

Guilherme Seminatti ${ }^{1}$, Rafaela de Souza Barbosa ${ }^{1}$, Thayná Victoria Silva do Nascimento ${ }^{1}$, Marcelo Fabiano Andre ${ }^{1}$

\section{RESUMO}

O presente trabalho analisa um compilado de cenas de filmes, estabelecendo uma relação entre realidade e ficção sob a perspectiva da ciência das transformações, popularmente conhecida como química, com o objetivo de utilizá-las no processo de ensino-aprendizagem desta ciência. Para isso, foi realizada uma apresentação ao vivo no youtube, onde os trechos pudessem ser explicados cientificamente pelos licenciandos em química e participantes do PIBID do IFSP campus Catanduva, na IV Semana da Química da mesma instituição.

Palavras-chave: Combustão; Forças intermolecures; PIBID; Ácido-Base; Bioluminescencia; Ensino.

\begin{abstract}
This work analyzes a compilation of movie scenes, establishing a relationship between reality and fiction from the perspective of the science of transformations, popularly known as chemistry, with the aim of using them in the teaching-learning process of this science. For this, a live presentation was made on youtube, where the excerpts could be explained scientifically by undergraduates in chemistry and participants of the IPTIS of the FISP Catanduva Campus, in the IV Chemistry Week of the same institution.
\end{abstract}

Keywords: Combustion; Intermolecular forces; PIBID; Acid-Base; Bioluminescence; Teaching.

\section{INTRODUÇÃO}

Segundo Silvana (2013), docentes da área de Química discutem e entram em consenso sobre haver um problema em se abordar os conteúdos de química na escola. Despertar o interesse por parte dos discentes seguindo à risca os conteúdos programáticos é um empecilho considerável, uma vez que os conteúdos são densos e as escolas não possuem infraestrutura laboratorial para tornar essas aulas mais atrativas e interessantes. Utilizar a abordagem cinematográfica não é algo surpreendentemente inovador, este recurso já é utilizado por alguns professores e é bastante recorrente em canais do YouTube, como a Universidade da Química e o canal Nerdologia (SILVANA, 2013).

1Instituto Federal de Educação, ciência e tecnologia de São Paulo - Câmpus Catanduva. E-mail: guilherme.seminatti@aluno.ifsp.edu.br 
Levando em consideração a acessibilidade e facilidade que os jovens e crianças possuem para acessar os filmes, seja através das plataformas de streaming ou dos canais abertos, e que os filmes e animações são um dos pilares do entretenimento dos adolescentes e das crianças, utilizá-los com recurso pedagógico permite que os educadores explorem diversos assuntos da ciência e utilizem diferentes longas-metragens para abordar o assunto desejado (SILVANA, 2013).

Fazendo uso dos estudos de Jean Piaget, que em 1970, amplia o sentido da educação dizendo que sua função é formar sujeitos que criam recursos diferentes e não somente ficam limitados ao que seus antepassados fizeram, (BARROS, 2021), assim como Paulo Freire, que cita diversas vezes em suas entrevistas "não me apliquem, mas me reinventem", (KOHAN, 2019), os alunos do Programa Institucional de Bolsa de Iniciação à Docência (PIBID), propuseram uma palestra respaldada em cenas de filmes que possuíam conteúdos científicos visando a explicação destes trechos, estabelecendo ou não a veracidade de tais fatos estruturados nos pilares da ciência.

O objetivo deste trabalho é sugerir abordagens investigativas para o ensino de química a partir de cenas do cinema.

\section{O ENSINO DA QUÍMICA E O CINEMA}

A atualidade é repleta de inserção das tecnologias, provocando transformações, também, na educação. Diante desta realidade, os profissionais de educação são obrigados a refletir, constantemente, sobre as implicações educativas que os desenvolvimentos tecnológicos trazem para a sociedade em geral, e, para os ambientes educacionais de modo particular (SILVEIRA, 2020).

Segundo Silveira (2020), essas mudanças geram novas competências que são exigidas do professor, o qual necessita estar apto e aberto a novas abordagens e metodologias, essencialmente ao objetivo principal, os alunos, que estão vivenciando novos saberes, e assim demanda do educador uma flexibilidade à incorporação destas em sala de aula.

Neste sentido, Silveira (2020), Gerpe (2018) e Prazer (2018), refletem sobre as dificuldades que os alunos têm no entendimento da química, essa podendo ser gerada principalmente pelo alto grau de abstração para aprendizagem de determinados conteúdos, sendo assim, a discussão avança sobre o valor do professor relacionar o ensino de química ao cotidiano dos estudantes, possibilitando uma maior assimilação, que são muitas vezes consideradas complexas pelos alunos. 
Deste modo, é fundamental que o professor dessa área consiga estabelecer humanidades e as incertezas da ciência. Para isso, é necessário que, nas aulas, os alunos possam experimentar, desenvolver hipóteses e argumentar sobre conceitos científicos (GERPE, 2018).

Sabe-se, como visto em Prazer (2018), que o uso de recursos visuais no ensino de química, como as imagens, pode viabilizar a aprendizagem, sendo os discentes capazes de um maior conflito cognitivo quando abordados por essas.

A inserção destes recursos pode ser expressas, principalmente, por meio de filmes, vídeos ou cinema, facilitando a aprendizagem, porém, cabe ao educador usar este recurso de maneira adequada, demonstrando aos alunos que a obra cinematográfica seja não apenas um momento de diversão, mas também de obtenção do conhecimento (SILVEIRA, 2020).

Desta forma, cinema e sala de aula podem se complementar de maneira a tornar satisfatórios os objetivos a que se propõem. Ambos são espaços para socialização dos sujeitos e convergem em vários aspectos, entre eles: o cinema, pode ser visto como um espaço de acesso à cultura, diversão e expressão da arte; enquanto a sala de aula, pode ser compreendida como espaço de mediação do conhecimento. Os filmes podem contribuir com o professor dentro da sala de aula, e essa colaboração pode se dar de diversas maneiras, a depender do que é proposto pelo profissional (FERREIRA, 2017).

Logo, resguardadas as devidas diferenças entre o ambiente escolar e o cinema, a escola só tem a ganhar com a interação com o cinema, sobretudo no que se refere ao trabalho com as emoções, o mistério e a curiosidade que ele proporciona. Assim, a escola pode incorporá-lo em seus métodos e técnicas tendo em vista contribuir para aprendizagem dos alunos.

\section{METODOLOGIA}

Após a realização de pesquisas sobre as contribuições do cinema para o ensino de química, utilizando o Google Acadêmico, seguiu-se o presente trabalho buscando variedades de filmes que apresentassem cenas com conteúdo que causam questionamentos sobre a possibilidade de serem realizados ou não na realidade, através da química.

Selecionou-se, então, nove cenas de filmes popularmente conhecidos, junto das justificativas das possíveis realizações, quimicamente falando, de cada trecho dos filmes. 
Além disso, para cada cena que não poderia ser reproduzida apresentou-se motivos científicos para a impossibilidade.

Com isso, foi elaborada uma apresentação, utilizando a plataforma Genialy, para ser exibida no Youtube, na IV Semana da Química do IFSP campus Catanduva, como uma parceria com os participantes do PIBID da mesma instituição.

Durante a apresentação ao vivo, exibiu-se a proposta de cada cena, e ainda se responderam perguntas realizadas pelos ouvintes sobre as explicação acerca dos filmes e, também, sobre a participação do PIBID durante a vida acadêmica de cada aluno.

\section{RESULTADOS E DISCUSSÃO}

O levantamento bibliográfico resultou em mais de 10 artigos que citavam a potencialidade presente nas esferas cinematográficas para o ensino de conteúdos da química, como bioluminescência, transformações químicas e diversos outros tópicos que estão presentes no ensino médio e no cotidiano dos alunos.

Os filmes escolhidos e os conteúdos abordados encontram-se na Tabela 1.

Tabela 1 - Filmes e conteúdos abordados

\begin{tabular}{c|c}
\hline Filme & Conteúdo abordado \\
\hline Cruella (2021) & $\begin{array}{c}\text { Transformação química da celulose em } \\
\text { trinitrocelulose }\end{array}$ \\
\hline Star Wars - O retorno do Jedi (1983) & $\begin{array}{c}\text { Composição do espectro de fogo e composição } \\
\text { do universo }\end{array}$ \\
\hline Avatar (2009) & Quimiluminescência e Bioluminescência \\
\hline Batman (1989) e Esquadrão Suicida (2016) & Substâncias ácidas e básicas \\
\hline Homem-Aranha (2002) & Forças intermoleculares de Van Der Waals \\
\hline Homem-Aranha 2 (2004) & Isótopos do Hidrogênio \\
\hline Quarteto Fantástico (2005) & Temperatura de transição vítrea \\
\hline Operação Big Hero (2014) & laboratórios \\
\hline Megamente (2010) & Reação de desidratação \\
\hline
\end{tabular}

Fonte: Autores (2021) 
A plataforma Genialy foi utilizada para criar a apresentação e visou-se a utilização de recursos visuais atrativos e próximos à realidade do filme trabalhado, com o intuito descrito por Sbrogio (2021), em manter uma linguagem de leitura linear que medie a aprendizagem, mesmo a distância, com a tendência de o uso de recursos interativos e mais atrativos complementam a aprendizagem significativa.

O primeiro filme apresentado foi Cruella (2021), a cena apresentada, em que Cruella coloca fogo em um sobretudo branco revelando seu vestido vermelho, foi repercussão nas redes sociais e com isso percebeu-se que poderia ser utilizada como atrativo para o ensino de química, a Figura 1 A e B ilustra a cena apresentada e a apresentação desenvolvida.

Figura 1A - Cruella em Chamas

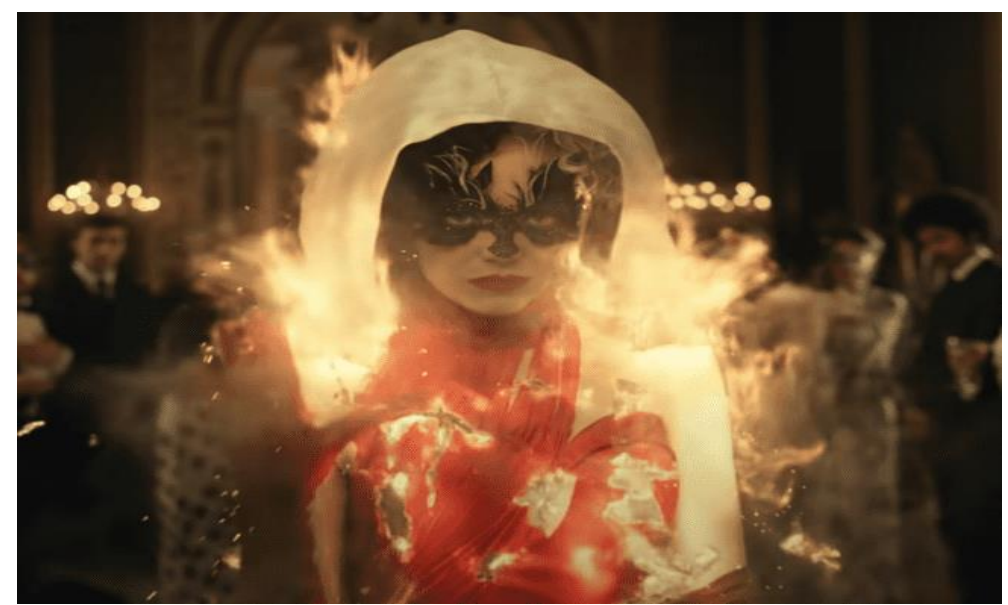

Fonte: YouTube (2021)

Figura 1B - Apresentação Cruella

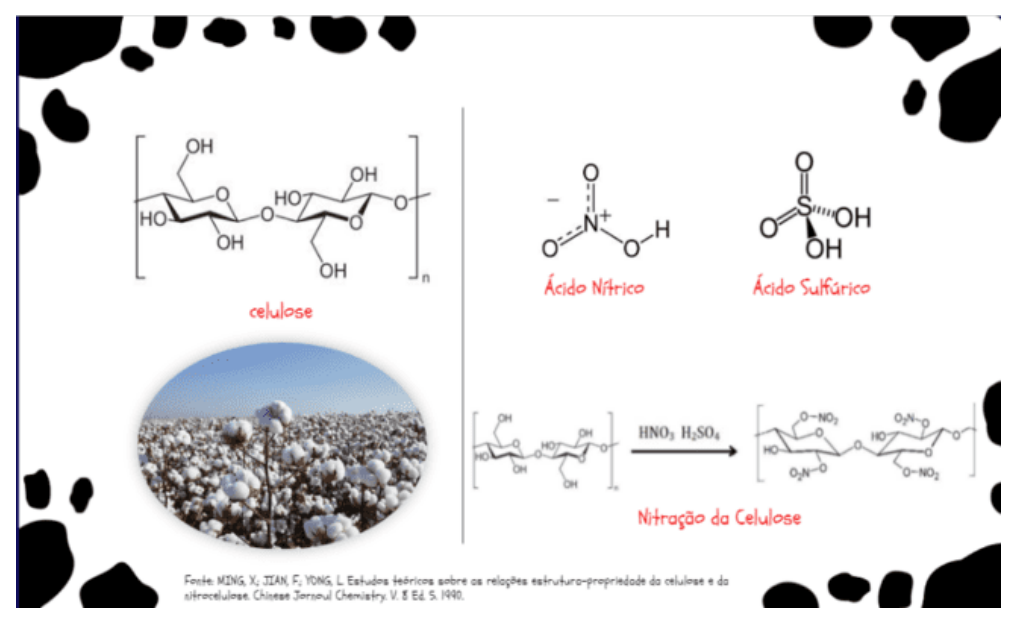

Fonte: Autores (2021)

A explicação dessa cena de filme foi feita introduzindo o fato do cotidiano do uso de celulose na fabricação de roupas como visto em Daniel (2018) e se seguiu com Ming (1990), que explica a ação do íon nitrônio, gerado pelo ácido nítrico em meio de ácido sulfúrico, na celulose e assim, produz a trinitrocelulose, que é apelidada de algodão 
pólvora, por sua característica altamente inflamável. Sendo assim, essa cena foi classificada junto dos ouvintes como sendo possível de ser realizada na realidade com o auxílio da química.

Já no caso de STAR WARS (1983), a cena apresentada foi a explosão da estrela da morte, arma utilizada no filme pelo vilão Darth Vader para explodir planetas, a Figura 2 A e B demonstra a cena e a apresentação desenvolvida.

Figura 2A - Explosão da estrela da morte

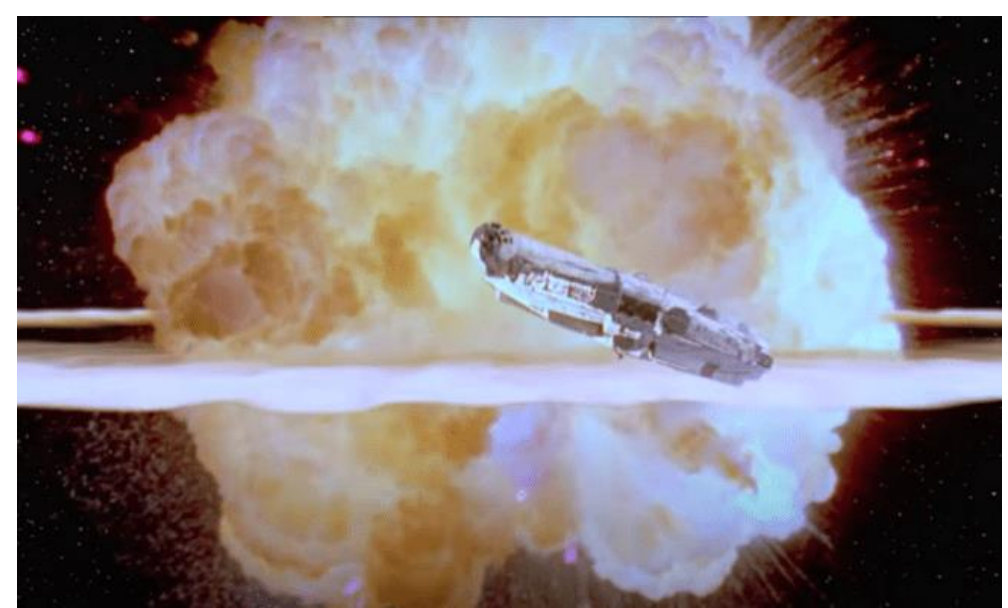

Fonte: Youtube (1983)

Figura 2B - Apresentação composição do fogo.

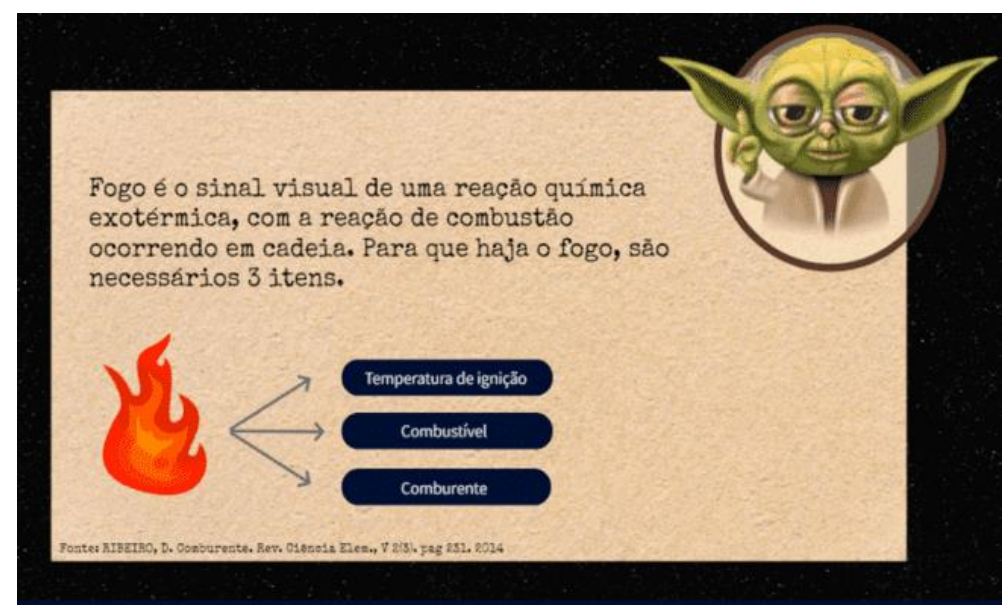

Fonte: Autores (2021)

Apresentou-se o conceito da composição do fogo, que segundo Ribeiro (2014), se trata de três compostos ou etapas, sendo esses, a Temperatura de Ignição, responsável por iniciar a reação fornecendo agitação das moléculas do composto; combustível, o material a ser consumido, podendo ser hidrocarbonetos, celulose e diversos outros; e por fim o comburente, este um gás com característica eletronegativa que irá reagir com os gases liberados no processo e produzir o espectro do fogo visível. 
$\mathrm{Na}$ atmosfera terrestre o comburente utilizado é o oxigênio $\left(\mathrm{O}_{2}\right)$, entretanto, quando analisado a composição química do universo se percebe junto de Lazzaro (2002), que não é possível encontrar esses gases eletronegativos no espaço, sendo assim, essa cena foi classificada como não possível químicamente.

A Figura 3A e B ilustra o terceiro filme, AVATAR (2009), na cena em que os personagens estão andando pela floresta em período noturno e diversas luzes começam a aparecer.

Figura 3A - Cena do filme avatar em período noturno

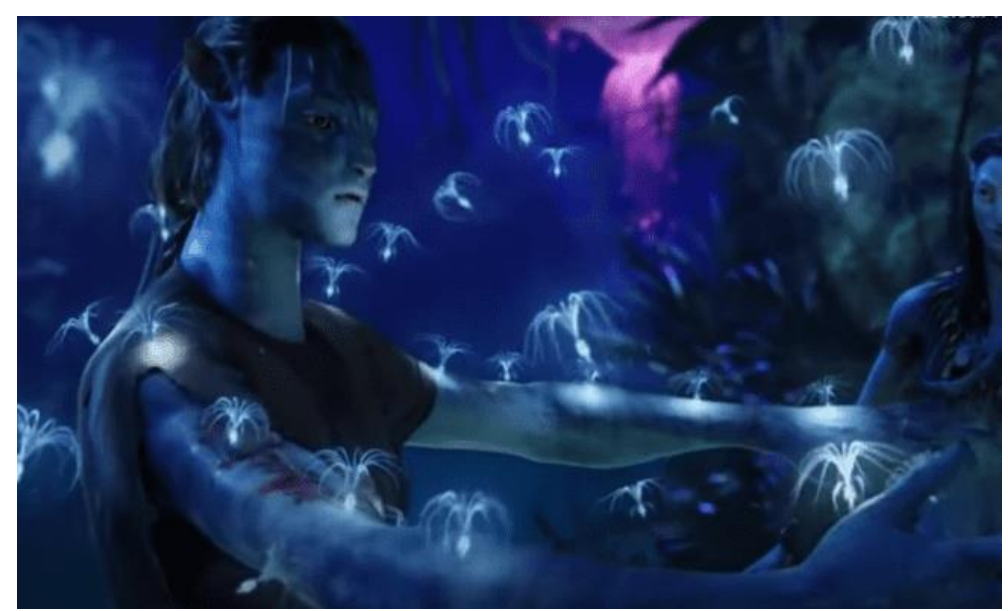

Fonte: Youtube (2009)

Figura 3B - Apresentação bioluminescência

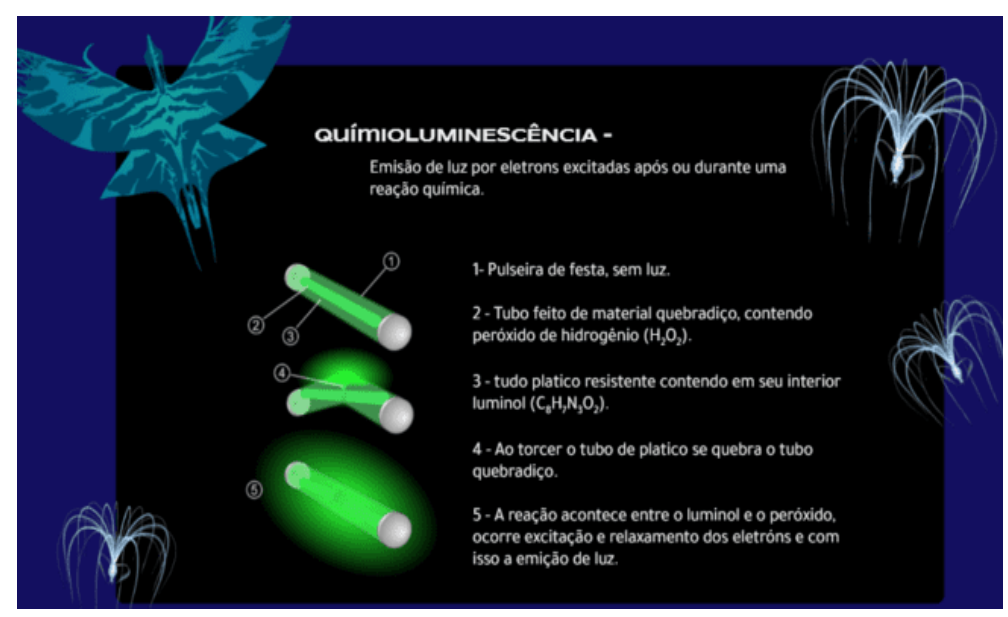

Fonte: Autores (2021)

Diante dessa cena, os conceitos de quimioluminescência foram introduzidos e exemplificados ao cotidiano, para logo em seguida ser abordado a possibilidade da bioluminescência, como uma quimioluminescência realizada por organismos vivos. Sendo esse, contemplado como efeito possível de realização no mundo real.

No mundo dos heróis muitos conteúdos podem ser encontrados, e com esse intuito inclui-se os filmes BATMAN (1989) e ESQUADRÃO SUICIDA (2016), com cenas 
muito semelhantes e que se replicam diversas vezes no mundo do cinema, um tanque de ácido, como possível visualizar nas Figuras 4A, B e C.

Figura 4A - Cena do filme Batman

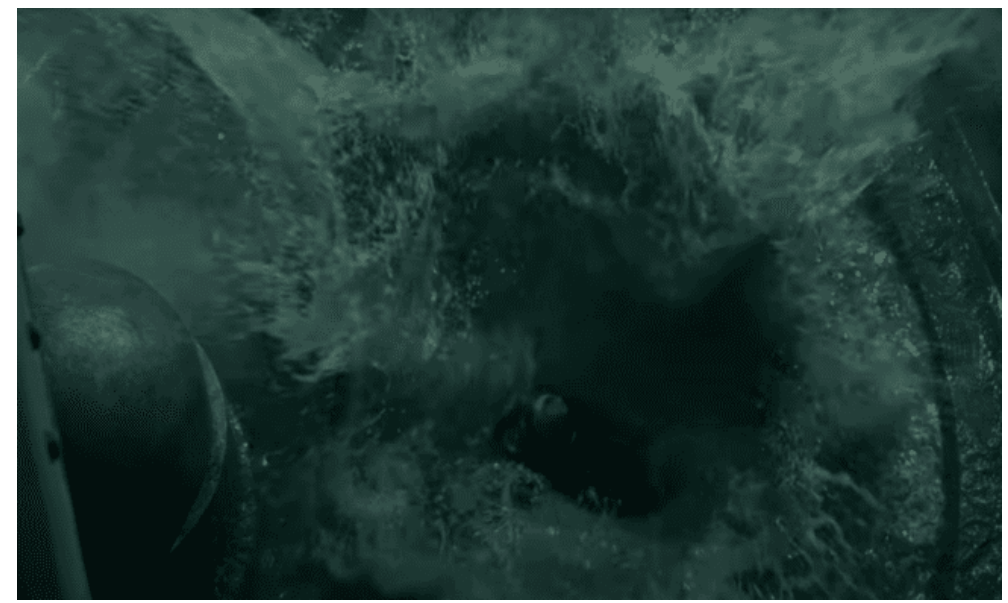

Fonte: YouTube (1989)

Figura 4B - Cena do filme Esquadrão Suicida

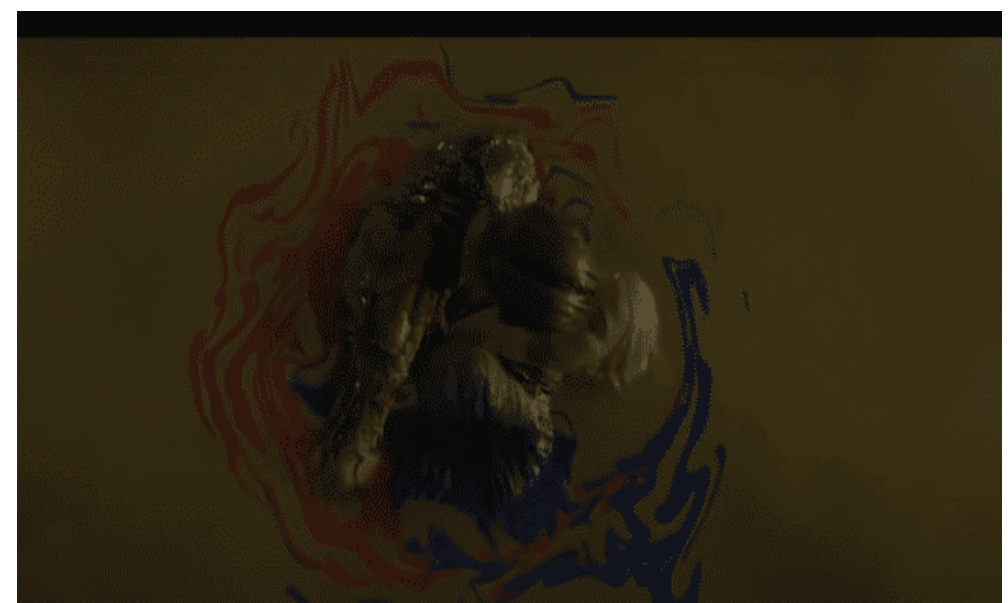

Fonte: YouTube (2016)

Figura 4C - Apresentação tanque de ácido

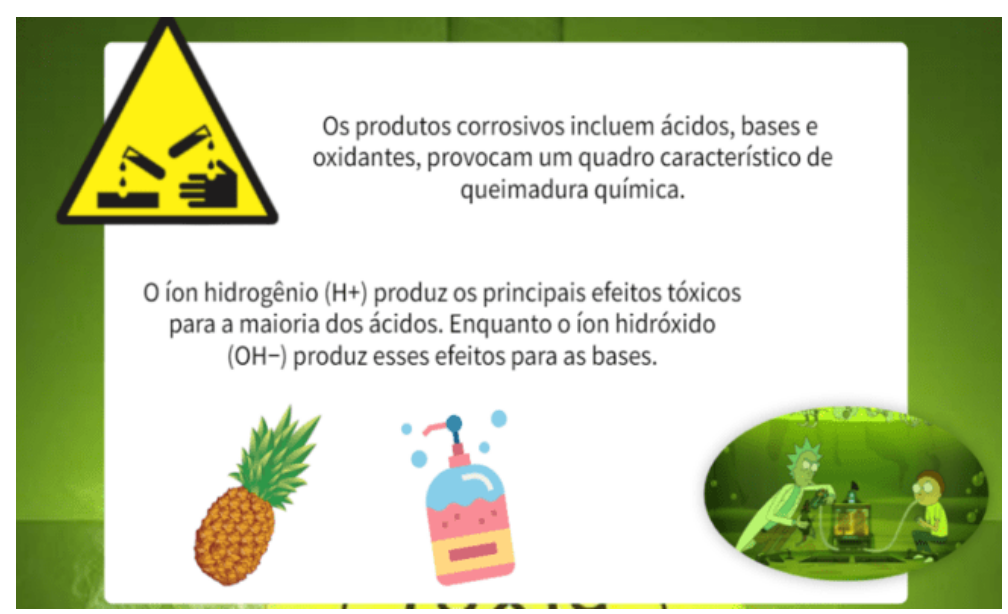

Fonte: Autores (2021) 
Inicialmente, foi comentado aspectos do filme e em seguida apresentado exemplos do cotidiano de itens ácidos e básicos, com o intuito de desmistificar o senso comum, como visto em Velanes (2017), muitos conhecimentos prévios de alunos pautam essa crença que ácidos são corrosivos, sem exceções. Procedendo a isso, explicou-se que diversas substâncias podem ter características ácidas, contudo, não são corrosivas e com esse intuito revelou-se que cenas assim podem ocorrer na realidade, entretanto, dependendo não apenas de ser uma substância ácida, mas sim sua concentração, e diversos outros aspectos.

O próximo filme foi HOMEM-ARANHA (2002), como pode ser visto nas Figuras $5 \mathrm{~A}$ e B.

Figura 5A - Cena do filme Homem-Aranha

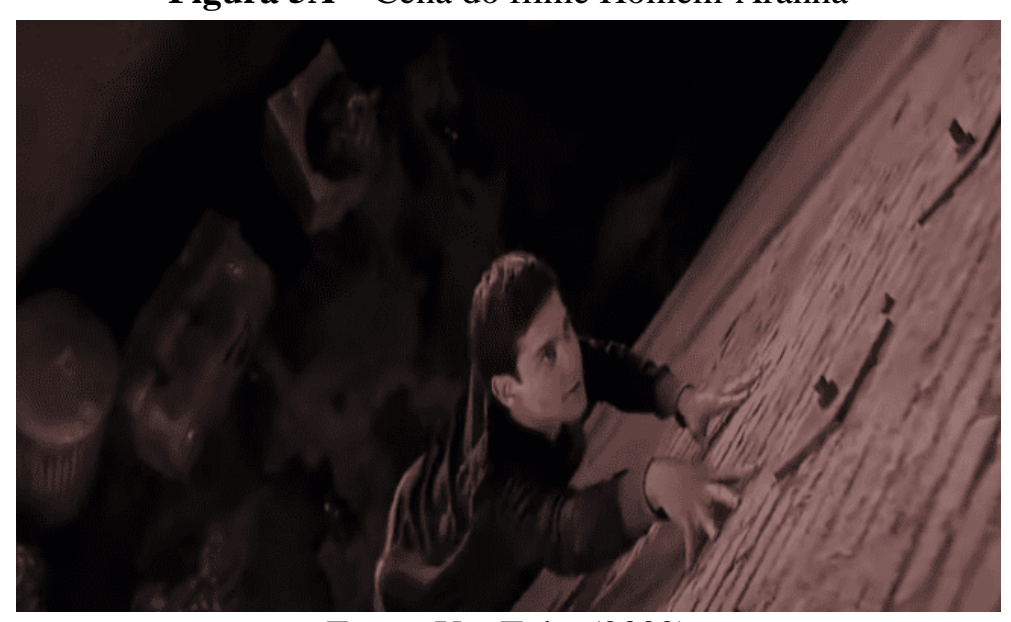

Fonte: YouTube (2002)

Figura 5A - Apresentação Homem-Aranha

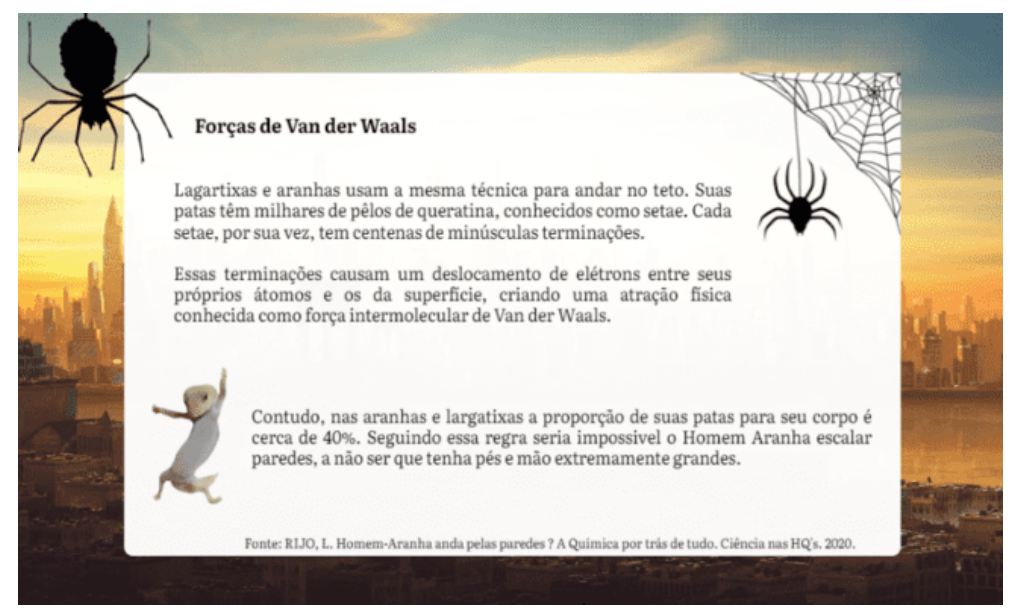

Fonte: Autores (2021)

O filme apresenta um conceito muito presente no cotidiano e sua análise se fez fruto de diversas comparações, de acordo com Rijo (2020), a cena não pode ocorrer na realidade. Isto porque o princípio mostrado no filme para o herói andar nas paredes seria semelhante a das aranhas e lagartixas, que possuem os setaes, pelos de queratina, que 
podem realizar um deslocamento de elétrons, gerando um momento dipolo e ficando suspensas pela interação intermolecular descrita pelas forças de Van Der Waals, contudo, a proporção corporal de uma aranha ou lagartixa para o Homem aranha, torna essa explicação insuficiente, sendo assim, não seria possível.

HOMEM-ARANHA 2 (2004), foi o próximo filme, ilustrado nas Figuras 6A e B.

Figura 6A - Cena do filme Homem-Aranha 2

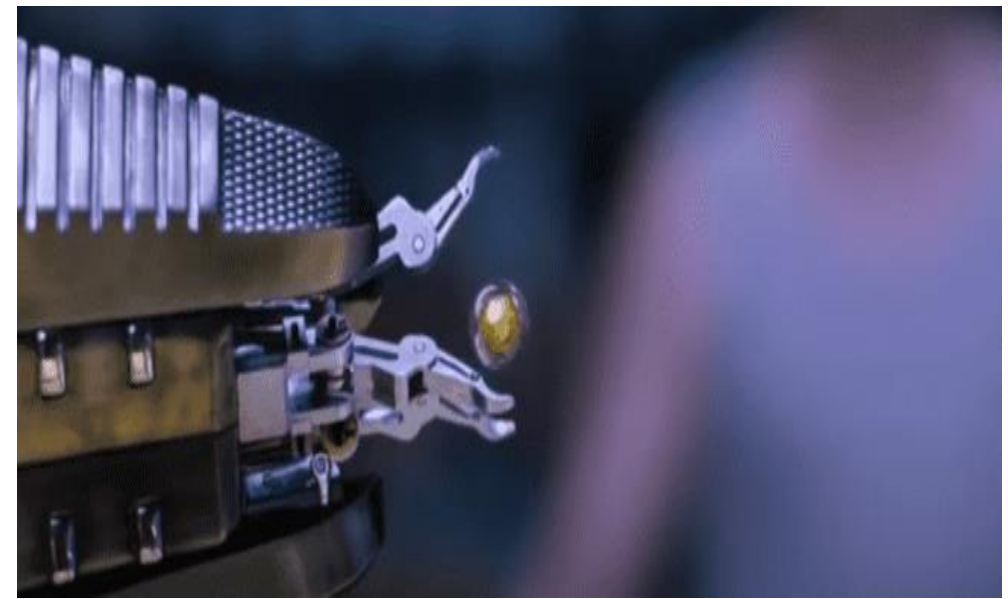

Fonte: YouTube (2004)

Figura 6B - Apresentação isótopos do hidrogênio.

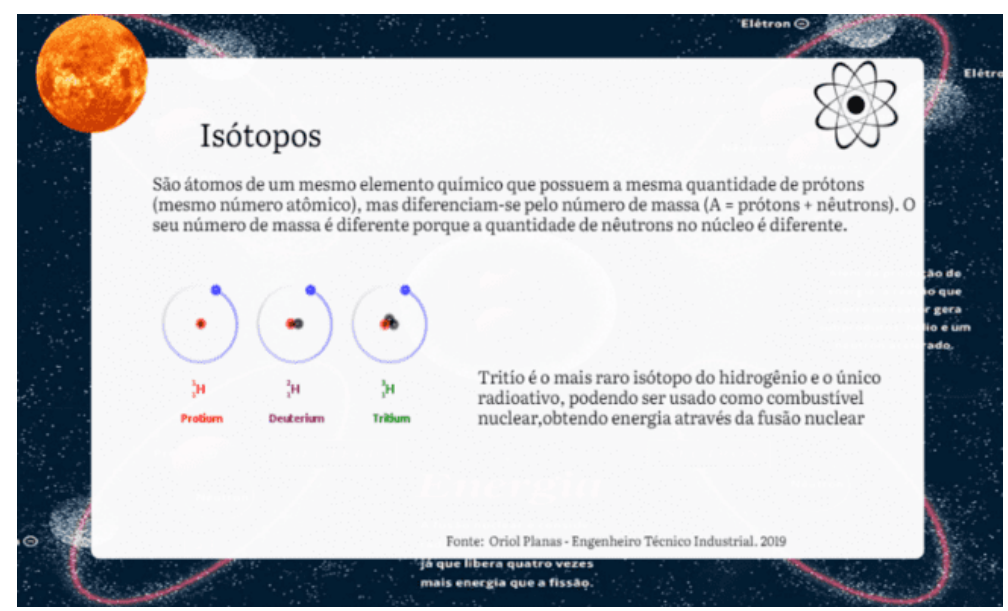

Fonte: Autores (2021)

A cena apresentada demonstra um estereótipo, como visto em Brasil (2020), o cientista é representado como um gênio engenhoso, que pode vir a se tornar um vilão em qualquer instante, essa visão dos produtores de ciência pode vir a produzir um distanciamento dos alunos para a comunidade científica.

Ainda assim, a cena demonstra um item com nome peculiar chamado de tritium, esse serviu de abordagem para o conteúdo de isótopos, em que se foi explicado as possíveis diferenças de massa por alteração de prótons e nêutrons no núcleo de um átomo, e o filme foi classificado como sendo próximo da realidade encontrado na ciência. 
Ainda no mundo dos heróis, seguiu-se para QUARTETO FANTÁSTICO (2005), como se pode ver nas Figuras 7A e B.

Figura 7A - Cena do filme Quarteto Fantástico

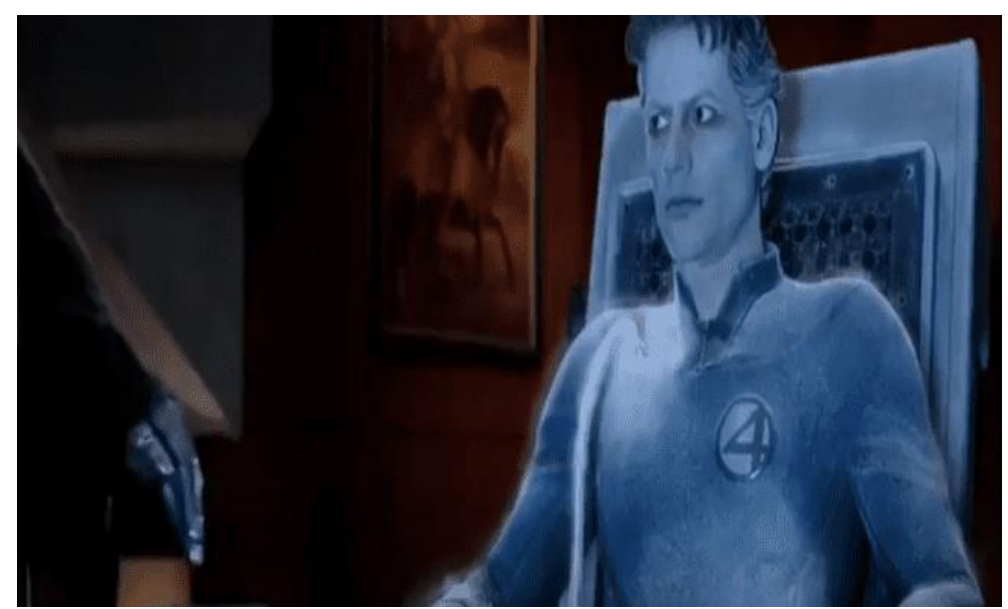

Fonte: Youtube (2005)

Figura 7B - Apresente transição vítrea

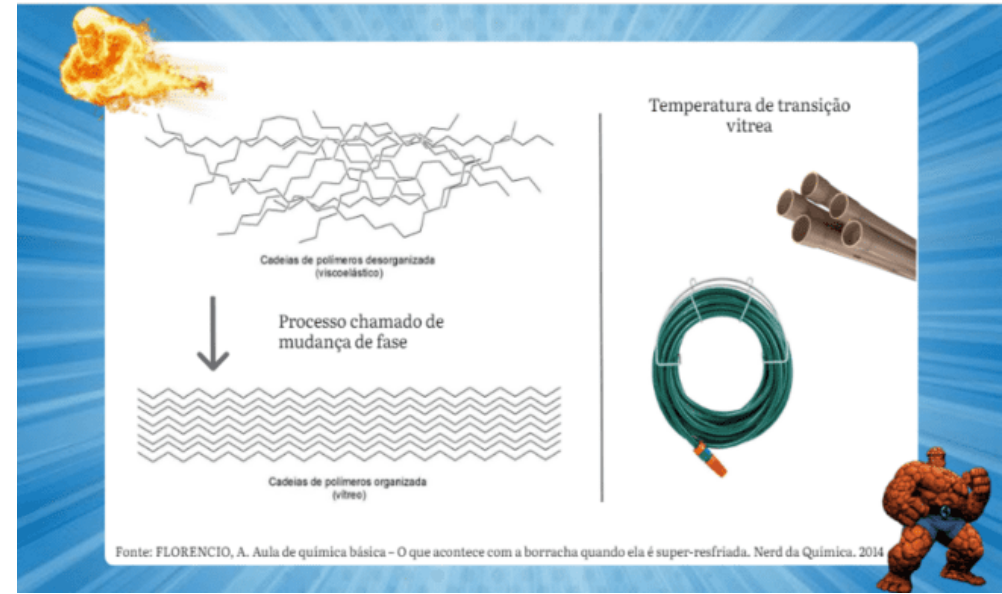

Fonte: Autores (2021)

O filme trabalha em diversos momentos com conteúdo de física e química que podem ser usados para abordagem, neste em específico apresentam o conceito de transição vítrea por temperatura, segundo Florencio (2014), itens de borracha são compostos por polímeros, esses podem estar organizados ou dispersos, no primeiro caso a substância tem propriedades vítreas sendo quebradiço, no segundo caso apresenta propriedades viscoelásticas e pode sofrer manipulação. Esse estado, entretanto, não é fixo, alterações de temperatura podem vir a modificar suas propriedades.

No gênero das animações também se encontram muitos conteúdos, com potencialidades de abordagens para Química, exemplo disse é o filme BIG HERO (2015), que às Figuras 8A e B ilustram. 
Figura 8A - Cena do filme Big Hero

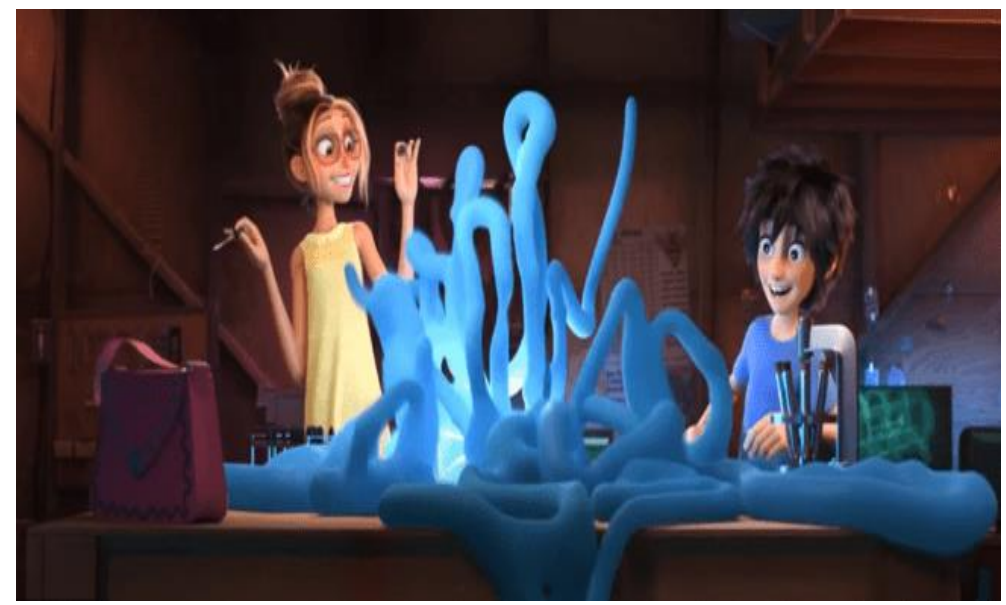

Fonte: YouTube (2015)

Figura 8B - Apresentação Big Hero

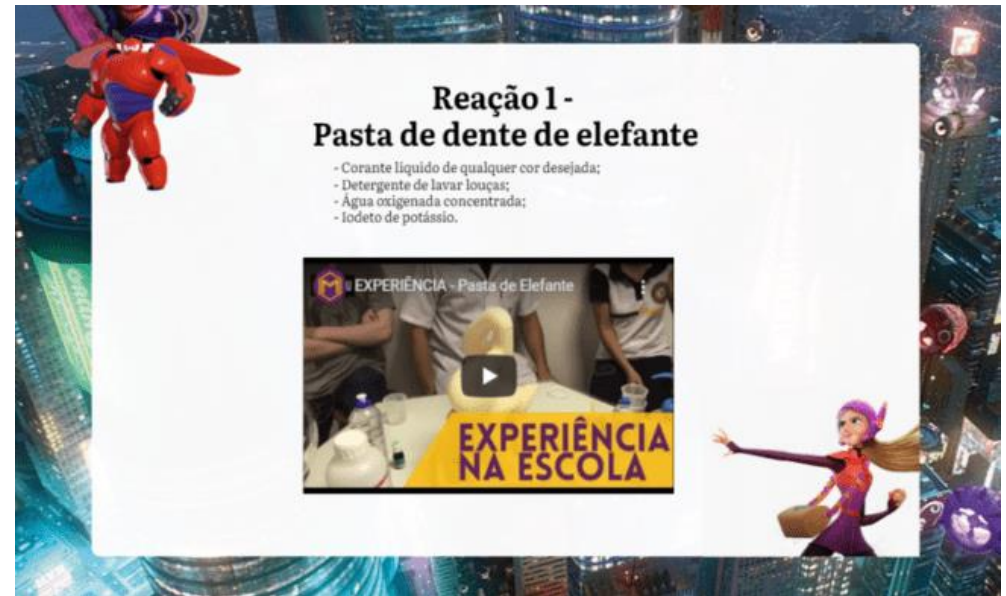

Fonte: Autores (2021)

Nota-se um diferencial neste filme, a cientista trata-se de uma mulher, quebrando alguns sensos comuns já comentados ao longo deste trabalho, e podendo, como citado por Cruz (2019), servir como identificação para estudantes mulheres a se aproximarem dos conteúdos de ciências da natureza. Além disso, o filme transporta diversas cenas de produção de química experimental, abordagem utilizada para classificar o filme como sendo possível na realidade, embora, ressalta-se a importância de uma medida de segurança para o transporte de substâncias químicas.

Para finalizar a apresentação trouxe-se o filme MEGAMENTE (2010), possível de se ver nas Figuras 9A e B. 
Figura 9A - Cena do filme Megamente

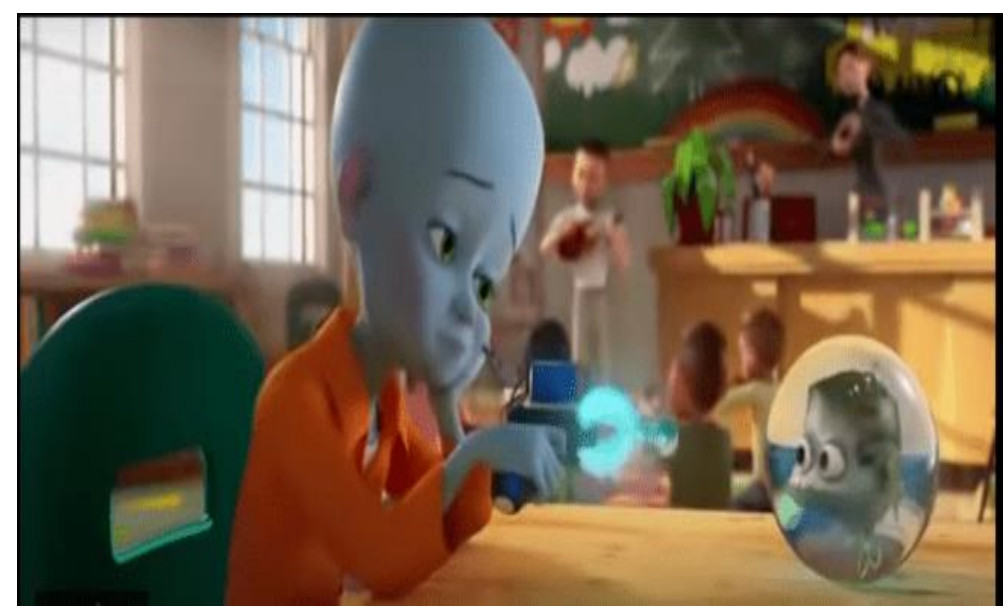

Fonte: YouTube (2010)

Figura 9B - Apresentação desidratação

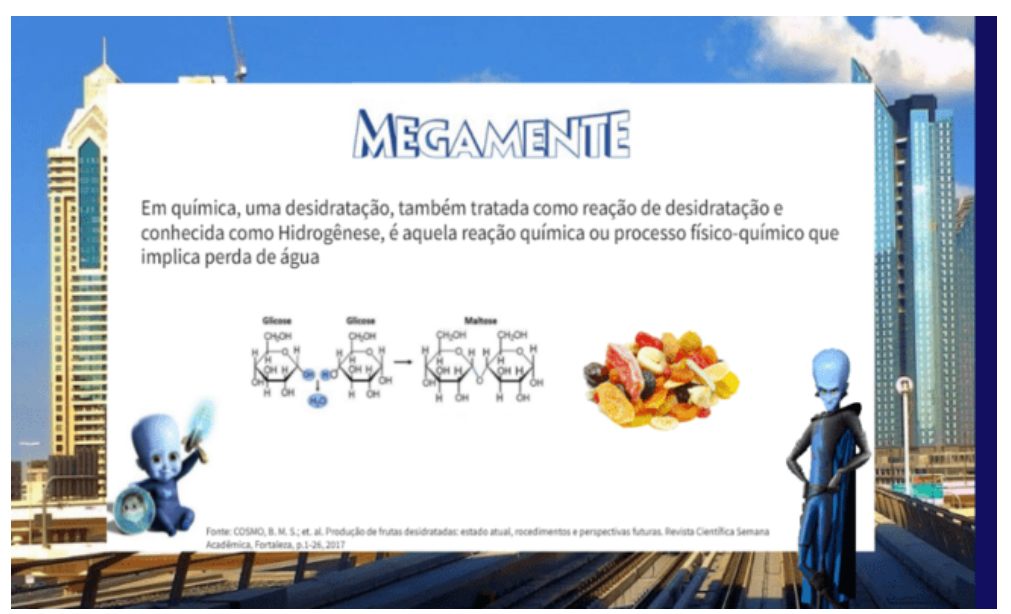

Fonte: Autores (2021)

Seguiu-se para a explicação, de acordo com Cosmo (2017), que apresenta uma breve explicação sobre as reações químicas de hidratação e desidratação, citadas no filme, porém, no filme o personagem principal é capaz de desidratar e hidratar seres vivos com o uso de um laser e água, algo muito distante da realidade da química, embora reações assim ocorram no cotidiano, não são com essa simplicidade demonstrada na cena, sendo assim classificado como não possível de reprodução fora das telas cinematográficas.

Embora o trabalho tenha se objetificado em desvendar situações do cinema em que consistem com a realidade encontrada na ciência, este não deve ser utilizado como fonte para críticas aos roteiros e realidades desenvolvidas por estes, visto que o cinema se trata de uma expressão artística e, assim, possui licença poética para desenvolvimento de situações que destoam da realidade, assim como utopias e ficções que de forma análoga podem vir a manifestar críticas e sentimentos de identidade para a sociedade (JUNIOR, 2017). 
Contudo, deve-se ressaltar que mesmo com essa licença o cinema pode vir a criar barreiras e sensos comuns destoantes da realidade para os alunos, o que será gerador de uma dificuldade aos educandos, essa, porém como dito em Junior (2017), não se faz responsabilidade do cinema e sim do ambiente formal de ensino em prover situações em que o aluno possa questionar e analisar suas realidades.

Dentro dessa mesma discussão, ressalta-se a importância das produtoras cinematográficas em gerar identificação dentro da realidade dos cientistas. Isto é, que quebrem o senso comum de um cientista homem, branco e genial que não possui vida social e responsabilidades, para a realidade vivida por pesquisadores e produtores de ciência em nosso país e cotidiano (OLIVEIRA, 2020).

\section{CONCLUSÃO}

Após a realização da atividade, percebe-se que o uso de cenas cinematográficas como abordagem no ensino de química se faz satisfatório, uma vez que proporciona um momento de reflexão e investigação em torno do conteúdo de química de maneira descontraída promovendo grande interesse por parte dos ouvintes. Além disso, se mostra capaz de justificar as dúvidas obtidas pelo público acerca das cenas trabalhadas e, também, proporciona a desmistificação de fatos não passíveis de reprodução na realidade, aproximando esses do pensamento crítico-científico.

\section{REFERÊNCIAS}

AVATAR. James Cameron. Brasil (182 min.) 2009. Disponível em: <https://www.youtube.com/watch?v=HPnjysk3tRo> Acesso em: 21 de nov. de 2021.

BARROS, F. C.;VIEIRA, D.A. P. Os desafios da educação no período de pandemia. Brazilian Journal of Development, Curitiba, v. 7, n. 1, p. 826-849, jan. 2021.

BATMAN. Tim Burton. Brasil (126 min). 1989. Disponível em: <https://www.youtube.com/watch?v=rtoE48zUJjg\&list=PL8q2eooEfxaPElhU1QQ8T_4 No_WIXXAZT >. Acesso em: 24 de nov. de 2021.

BBC.COM, 11 de março de 2020. Coronavírus: A OMS declara pandemia. Disponível em: 〈https://www.bbc.com/portuguese/geral-51842518>. Acesso em: 22 de nov. de 2021.

BRASIL, K. B. N. "Desenhe um cientista": as concepções dos estudantes do centro juvenil de ciência e cultura sobre os cientistas. Cenas Educacionais, v. 3, p. 8670, 2020. 
COSMO, B. M. S.; et. al. Produção de frutas desidratadas: estado atual, procedimentos e perspectivas futuras. Revista Científica Semana Acadêmica, Fortaleza, p.1-26, 2017.

CRUELLA. Craig Gillespie. Walt Disney Company. Brasil (134 min.). 2021. Disponível em: <https://www.youtube.com/watch?v=gmRKv7n2If8>. Acesso em: 24 de nov. de 2021.

CRUZ, L. D. L. da; GOMES, E. F. Estrelas Além do Tempo: debatendo gênero, raça e ciência em espaços educativos. Revista de Estudos Universitários - REU, v. 44, n. 2, 2019.

ESQUADRÃO SUICIDA. David Ayer. DC Entertainment. Brasil (230 min.) 2016. Disponível em: 〈https://www.youtube.com/watch?v=y2Qgdg4kN-o>. Acesso em: 24 de nov. de 2021.

FERREIRA, B. COSTA, V. B. O cinema na formação de professores: Interfaces com o PIBID Química. Iniciação e Formação Docente. UFTM. 2017.

FLORENCIO, A. Aula de química básica - O que acontece com a borracha quando ela é super-resfriada. Nerd da Química. 2014.

GERPE, R. L. Luz, câmera e ação nas aulas de química: o cinema como ferramenta preventiva - educativa sobre drogas. (Monografia - Curso de Pós-Graduação em Ensino de Química) Instituto de Química- IQ, da Universidade Federal do Rio de Janeiro UFRJ. 2018.

HOMEM ARANHA 2. Sam Raimi. Brasil (127 min.) 2004. Disponível em: $<$ https://www.youtube.com/watch?v=e6-OmfSOWQk\&t=18s>. Acesso em: 24 de nov. de 2021.

HOMEM ARANHA. Sam Raimi. Brasil (121 min.) 2002. Disponível em: $<$ https://www.youtube.com/watch?v=7OGdwJ92wbU\&t=55s >. Acesso em: 24 de nov. de 2021.

JUNIOR, S. N.; NEVES, M. C. D. A subversão do tempo e do espaço no cinema: uma proposta interdisciplinar para o ensino da física. IV Simpósio Nacional de Ensino de Ciência e Tecnologia. Ponta Grossa. 2017.

KOHANN, Walter. Paulo Freire mais do que nunca: uma biografia filosófica. Belo Horizonte: Vestígio, 2019.

MEGAMENTE. Tom McGrath. DreamWorks Animation. Brasil (96 min). 2010). Disponível em: 〈https://www.youtube.com/watch?v=pjdjRtDjEWw>. Acesso em: 24 de nov. de 2021.

MING, X.; JIAN, F.; YONG, L. Estudos teóricos sobre as relações estruturapropriedade da celulose e da nitrocelulose. Chinese Jornoul Chemistry. V. 8 Ed. 5. 1990.

OLIVEIRA, L. G. S. Quem esse cinema pensa que eu sou? A importância do aquilombamento do audiovisual. (Tese de Conclusão de Curso) Bacharel em Radialismo. UFPR. 2020. 
OPERAÇÃO BIG ZERO. Chris Williams, Don Hall. Walt Disney Company. Brasil (102 min.) 2014. Disponível em: 〈https://www.youtube.com/watch?v=dzHB4j4fvOo>. Acesso em: 24 de nov. de 2021.

ORIOL. P. - Engenheiro Técnico Industrial. 2019.

PRAZER, N. S.; RIBEIRO, H. SOUSA, A. C. M.; ROSA, I. S.; RODRIGUES, J. J.; SILVA, H. F. Cinema e Educação: uma atividade extensionista que promove a formação inicial e continuada. IX Congresso Regional de Extensão Universitária da região Centro Oeste. 2018.

QUARTETO FANTÁSTICO Josh Trank. Marvel Entertainment. Brasil (125 min.) 2005. Disponível em: <https://www.youtube.com/watch?v=jAxQykqH5nI>. Acesso em: 24 de nov. de 2021.

RIBEIRO, D. Comburente. Rev. Ciência Elem., v. 2, n. 3, p. 231, 2014.

RIJO, L. Homem-Aranha anda pelas paredes ? A Química por trás de tudo. Ciência nas HQ's, 2020.

SANTOS, R. M. S.; SANTOS, F. M.; COSTA, M. F. D. Quimiluminescência e bioluminescência. Química Nova, v. 16, n.3, p. 200-209, 1993.

SBROGIO, R. O. Design e ensino-aprendizagem: Entre slides e formação de professores. (Doutorado) Faculdade de Arquitetura, Artes, Comunicação e Design FAAC, da Universidade Estadual Paulista "Júlio de Mesquita Filho" - UNESP. 2021.

SILVA, D. S.; SILVA, M. V.; SOARES, C. A. O cinema e os quadrinhos: ferramentas alternativas para o ensino de química, 2013.

SILVEIRA, P. Química e Cinema: Um estudo sobre as possibilidades de inserção do filme perdido em Marte nas aulas de Química. (Mestrado - Ensino de Ciências e Matemática) Universidade Federal de Uberlândia. 2020.

STAR WARS: Episódio VI - O Retorno do Jedi. Richard Marquand. George Lucas. Lucas Films. Brasil (133 min.). 1983. Disponível em:

<https://www.youtube.com/watch?v=W7SntynLZQU>. Acesso em: 24 de nov. de 2021.

UNICEF.ORG, 27 de agosto de 2020. Covid-19: Pelo menos um terço das crianças em idade escolar não consegue acessar o ensino a distância durante o fechamento das escolas, diz novo relatório da Unicef. Acesso em: 22 de novembro de 2021.

VELANES, D. A ruptura na química entre o senso comum e o conhecimento científico a partir da análise de Gastón Bachelard. Griot : Revista de Filosofia, v. 15, n. 1, p. 187203, 2017. 